\title{
Effects of Snake-Derived Phospholipase A2 Inhibitors on Acute Pancreatitis: In vitro and in vivo Characterization
}

This article was published in the following Dove Press journal:

Drug Design, Development and Therapy

\section{Yanping Wu \\ Gen-You Liao \\ Hua-jing Ke \\ Pi Liu}

Department of Gastroenterology, The First Affiliated Hospital of Nanchang University, Nanchang 330006, People's Republic of China
Correspondence: Pi Liu

Department of Gastroenterology, The First Affiliated Hospital of Nanchang University, 17 Yongwaizheng Street, Donghu District, Nanchang 330006, Jiangxi Province, People's Republic of China

Tel +86-79l-3969l 45

Email liupi I26@sina.com
Objective: We aimed to investigate the effects of snake-derived phospholipase A2 inhibitor (PLA2) from Sinonatrix percarinata and Bungarus multicinctus on acute pancreatitis in vivo and in vitro and assess the mechanisms.

Methods: The levels of platelet-activating factor (PAF) and tumor necrosis factor (TNF)- $\alpha$ were detected by ELISA, and the characteristics of autophagy were detected by transmission electron microscopy and Western blotting (LC3, p62, and ATG5).

Results: In vitro experiments showed that PLA2 treatment caused obvious formation of autophagic bodies. By contrast, Sinonatrix and Bungarus peptides reduced the number of autophagic bodies. The concentrations of PAF and TNF- $\alpha$, and the expressions of p62, autophagy-related 5 (ATG5), and microtubule-associated protein 1A/1B-light chain 3 (LC3)II/LC3I in the PLA2-treated group were significantly higher than in the control group $(\mathrm{P}<0.05)$. The concentrations of PAF and TNF- $\alpha$, and the expressions of p62, ATG5, and LC3II/LC3I in the Sinonatrix or Bungarus peptide treatment groups were significantly lower than in the PLA2treated cells $(\mathrm{P}<0.05)$. In the pancreatic tissue, autophagic bodies were observed in the model group; autophagic bodies were remarkably reduced in Sinonatrix or Bungarus peptide-treated groups compared with the model group. In vivo experiments also showed that the levels of PAF and TNF- $\alpha$, and the expressions of p62, ATG5, and LC3II/LC3I were significantly higher in the model group than in the control group $(\mathrm{P}<0.05)$. The levels of PAF and TNF- $\alpha$ in the model group, and the expressions of p62, ATG5, and LC3II/LC3I in Sinonatrix or Bungarus peptidetreated groups were significantly lower than in the model group $(\mathrm{P}<0.05)$.

Conclusion: Sinonatrix or Bungarus peptide could ameliorate the features of acute pancreatitis, likely through regulating autophagy.

Keywords: PLA2, snake-derived PLI, acute pancreatitis, autophagy

\section{Introduction}

Acute pancreatitis (AP) is an inflammatory reaction that causes edema, hemorrhage, and even necrosis in pancreatic tissue after activation of pancreatin. ${ }^{1}$ The overall mortality of AP is about $5-10 \% .^{2}$ Clinically, about $20 \%$ of patients develop severe AP (SAP) characterized by pancreatic necrosis and organ failure, ${ }^{2}$ and the mortality rate in this group rises to $25-30 \%$. Currently, there are no specific drugs for the treatment of SAP. ${ }^{3}$ Therefore, finding new treatment options for SAP is both urgent and necessary.

Systemic inflammatory response syndrome (SIRS) and pancreatic necrosis are the central pathophysiological features of SAP. Phospholipase A2 (PLA2) plays an important role in this process and is considered a therapeutic target for SAP. ${ }^{4}$ 
Patients bitten by snakes can also have symptoms of SIRS and tissue necrosis, which is similar to the pathophysiological process of SAP. ${ }^{5}$ Abundant PLA2 is detected in venoms of most snakes. ${ }^{5}$ PLA2 in snake venom generally belongs to the sPLA2IIB, sPLA2IA, and sPLA2IIA types, ${ }^{6}$ which are either the same or consistent with the types of human-derived sPLA2IB and inflammatory sPLA2-IIA; specifically, their structures and functions are very similar, in that snake-derived PLA2 can cause similar pathophysiological processes as $\mathrm{SAP}^{7}$

Phospholipase A2 inhibitor (PLI) synthesized by the snake liver is a kind of glycoprotein that can specifically bind to the central region of PLA2. ${ }^{8}$ At present, 21 kinds of PLI are identified in snake serum based on the ExPASY protein database. ${ }^{9}$ PLI can also be divided into three categories: PLI$\alpha$, PLI- $\beta$, and PLI- $\gamma$. PLI- $\alpha$ and PLI- $\beta$ exist in Viperidae, and they mainly inhibit the activity of sPLA2; PLI- $\gamma$ exists in Ophiuchidae, cobra family, and python family, and the range of PLA2 inhibition is wide, including snake sPLA2, mammal PLA 2IIB and IIA, bee venom PLA2. ${ }^{10,11}$

Sinonatrix percarinata and Bungarus multicinctus are two common types of venomous snakes in Jiangxi Province (China). PLIs were screened from these two types of snakes and the key "motif" of these types of PLI was sequenced. In this study, we intended to investigate the effects of snake-derived phospholipase A2 inhibitor from $S$. percarinata and B. multicinctus on AP in vivo and in vitro and assess the mechanisms.

\section{Materials and Methods}

\section{Cells and Animals}

Rat pancreatic acinar-like cells (AR42J cells) were purchased from Beina Cell Bank (bncc100221, Beijing, China). Male C57BL/6 mice were purchased from Beijing Weitonglihua Experimental Animal Technology Co., Ltd. [scxk (Beijing) 2016-8006]. All animal experiments were performed in accordance with the Guide for the Care and Use of Laboratory Animals published by the Ministry of Science and Technology of China (2006), and these experiments were approved by the Ethics Committee of the First Affiliated Hospital of Nanchang University $(20,180,405)$.

\section{Experimental Groups}

Pancreatic acinar cells cultured with lysophosphatidylcholine (LPC) were always utilized to model AP in vitro, and PLA2 was thought to be the main toxin after modeling. ${ }^{12,13}$ Therefore, PLA2 (Aladdin, P128568, Shanghai, China) was directly used to model AP in this study. The optimal treatment time of PLA2 was screened using the flow cytometry experiment. The in vitro experiment was divided into four groups: a control group; a PLA2 group; a PLA2+peptide 1 group; and a PLA2+peptide 2 group. Briefly, $1 \times 10^{7}$ cells in each dish were treated with PLA2 $(1.75 \mu \mathrm{L}, 100 \mu \mathrm{g} / \mathrm{mL})$ for $1 \mathrm{~h}$. In PLA2+peptide groups, the cells were treated with PLA2 followed by $0.1 \mu \mathrm{g} / \mathrm{mL}$ peptides ( $1 \mathrm{~h}$ after PLA2) for $24 \mathrm{~h}$. The Sinonatrix peptide (Sequence: PGLPFSQLNGYSCPGV, P5401-1) and Bungarus peptide (Sequence: HGQPL SLPNGYHCPGI, P5401-2) were synthesized by Shanghai Sangon (Shanghai, China).

\section{Acute Pancreatitis Mouse Model}

The mouse model of AP was established as previously described. ${ }^{14}$ After weighing, mice were intraperitoneally injected with cerulein at a dose of $50 \mu \mathrm{g} / \mathrm{kg}$ (six times at 1-h intervals). After the last injection, lipopolysaccharide was injected intraperitoneally at the dose of $10 \mathrm{mg} / \mathrm{kg}$.

The in vivo experiments were carried out in the following groups: a control group; model group; and treatment groups $(20 \mathrm{mg} / \mathrm{kg}, 30 \mathrm{mg} / \mathrm{kg}$, and $40 \mathrm{mg} / \mathrm{kg}$ of Sinonatrix peptide and Bungarus peptide). Different doses of Sinonatrix peptide and Bungarus peptide were intraperitoneally injected following the first injection of cerulean. After $24 \mathrm{~h}$ of LPS injection, the animals were anesthetized with 5\% isoflurane and decapitated. The concentrations of platelet-activating factor (PAF) and TNF- $\alpha$ in the blood were detected by ELISA, and microtubule-associated protein 1A/1B-light chain 3 (LC3), p62, and autophagy related 5 (ATG5) expression were detected by Western blotting.

\section{ELISA}

PAF and TNF- $\alpha$ levels were detected following the instructions of the assay kits as previously described. ${ }^{15}$ The absorbance (OD) was measured at $450 \mathrm{~nm}$ wavelength.

\section{Transmission Electron Microscopy (TEM)}

After treatments, the cells or tissues were fixed using 2.5\% glutaraldehyde. After that, the cells or tissues were dehydrated, embedded, solidified, and sectioned into 70-nm slices, which were stained using 3\% uranyl acetate and lead citrate. The slides were imaged using transmission electron microscopy (80 kV, JEOL JEM-1230, Japan).

\section{Flow Cytometry}

AR42J cells were cultured in six-well plates at a concentration of $7 \times 10^{5}$ cells/well. When the cells were adhered to the well 
surface, PLA2 solution $(1.75 \mu \mathrm{L}, 100 \mu \mathrm{g} / \mathrm{mL})$ was added and incubated at $37^{\circ} \mathrm{C}$ for $1 \mathrm{~h}$. After that, the cells were digested and collected following centrifugation ( $1000 \mathrm{~g}, 3 \mathrm{~min}$ ). Briefly, $300 \mu \mathrm{L}$ of precooled $1 \times$ binding buffer cells were used to suspend the cells. Next, $3 \mu \mathrm{L}$ Annexin V-FITC and $5 \mu \mathrm{L}$ propidium Iodide (PI) were added to each tube. The cells were incubated at room temperature in the dark for $10 \mathrm{~min}$. Later, the cells were detected using flow cytometry (NovoCyte 2060R, ACEA Bioscience, Inc; Agilent).

\section{Western Blotting}

The proteins were extracted from the cells at $4^{\circ} \mathrm{C}$ for $30 \mathrm{~min}$. After centrifugation at $10,000 \mathrm{~g}$ for $10 \mathrm{~min}$, the total proteins were collected. The protein concentration was determined bicinchoninic acid assay (BCA) assay (Beyotime, Beijing, China). Thereafter, the proteins were run on SDS-PAGE for $1-2 \mathrm{~h}$ and transferred to a nitrocellulose membrane. The membranes were blocked in 5\% defat milk at room temperature for $2 \mathrm{~h}$. After that, the membranes were incubated with the following primary antibodies at $4^{\circ} \mathrm{C}$ overnight: mouse monoclonal anti-GAPDH (TA-08, 1/2000, ZSbio); rabbit polyclonal antiLC3 (ab48394, 1/1000, Abcam); rabbit polyclonal anti-p62 (ab109012, 1/10,000, Abcam); and rabbit polyclonal antiATG5 (ab108327, 1/5000, Abcam). Thereafter, the membranes were incubated with the following secondary antibodies at $4^{\circ} \mathrm{C}$ for $2 \mathrm{~h}$ : HRP-labeled goat anti-rabbit IgG (cat. no. 65-6120; Thermo Fisher Scientific, Inc.) or HRP-labeled goat anti-mouse IgG (cat. no. 31,430; Thermo Fisher Scientific, Inc.). The bands were visualized using an electrochemiluminescence kit (Beyotime, Beijing, China). The quantification of protein expression was conducted using the Quantity One software (v4.62; Bio-Rad Laboratories, Inc.) with $\beta$-actin as the loading control as previous described. ${ }^{16}$

\section{Statistical Analysis}

All data are expressed as mean \pm standard deviation. One-way ANOVA followed by Bonferroni correction was applied to determine statistical significance. A value of $\mathrm{P}<0.05$ was considered to indicate statistical significance. SPSS 19 (IBM Corp., Armonk, NY, USA) was used for statistical analysis.

\section{Results}

\section{Determination of the Treatment Condition with PLA2 in Rat Pancreatic Acinar Cells}

As shown in Figure 1, the apoptotic rate was the highest at $1 \mathrm{~h}$ after treatment of PLA2 $(100 \mu \mathrm{g} / \mathrm{mL})$. Therefore, this action time was selected in the subsequent experiments to investigate the protective effects of MSPLI.

\section{Screening the Doses of MSPLI Using an Animal Model}

As shown in Figure 2, PAF and TNF- $\alpha$ levels in the blood of the model group increased significantly as compared to the control group $(\mathrm{P}<0.05)$. However, treatment with $40 \mathrm{mg} / \mathrm{kg}$ Sinonatrix peptide or $40 \mathrm{mg} / \mathrm{kg}$ Bungarus peptide significantly reduced PAF and TNF- $\alpha$ levels when compared with the model group $(\mathrm{P}<0.05)$. Therefore, $40 \mathrm{mg} / \mathrm{kg}$ Sinonatrix peptide or $40 \mathrm{mg} / \mathrm{kg}$ Bungarus peptide was selected for the animal experiments.

\section{The Results of PAF and TNF- $\alpha$ Concentration in Cells and Pancreatic} Tissue

As shown in Figure $3 \mathrm{~A}$ and $\mathrm{B}$, the concentration of PAF and TNF- $\alpha$ in the cells treated with PLA2 was significantly higher than that in the control group $(\mathrm{P}<0.05)$. The concentrations of PAF and TNF- $\alpha$ in the Sinonatrix or Bungarus peptide groups were significantly lower than those in the control group $(\mathrm{P}<0.05)$. As shown in Figure $3 \mathrm{C}$ and $\mathrm{D}$, the level of PAF and TNF- $\alpha$ in the pancreatic tissue of the model group was significantly higher than that in the control group $(\mathrm{P}<0.05)$. The levels of PAF and TNF- $\alpha$ in the $40 \mathrm{mg} / \mathrm{kg}$ Sinonatrix or $40 \mathrm{mg} / \mathrm{kg}$ Bungarus peptide groups were significantly lower than those in the model group $(\mathrm{P}<0.05)$.

\section{Ultrastructure of Cells and Pancreatic Tissue}

As shown in Figure 4A, there was no obvious autophagic body formation in the control group. By contrast, autophagic body formation was observed in the PLA2 treatment group. There was a significant reduction in autophagic body formation in the peptide treatment groups compared with the model group.

As shown in Figure 4B, no autophagic bodies were observed in the pancreatic tissue of the control group. However, autophagic bodies were observed in the model group. The $40 \mathrm{mg} / \mathrm{kg}$ Sinonatrix and $40 \mathrm{mg} / \mathrm{kg}$ Bungarus peptide-treated groups showed a remarkable reduction in autophagic bodies when compared with the model group.

\section{Expression of LC3, P62, and ATG5 in} Cells and Animals

The expression of p62, ATG5, and LC3-II/I in the PLA2treated cell group was significantly higher than the control 
A
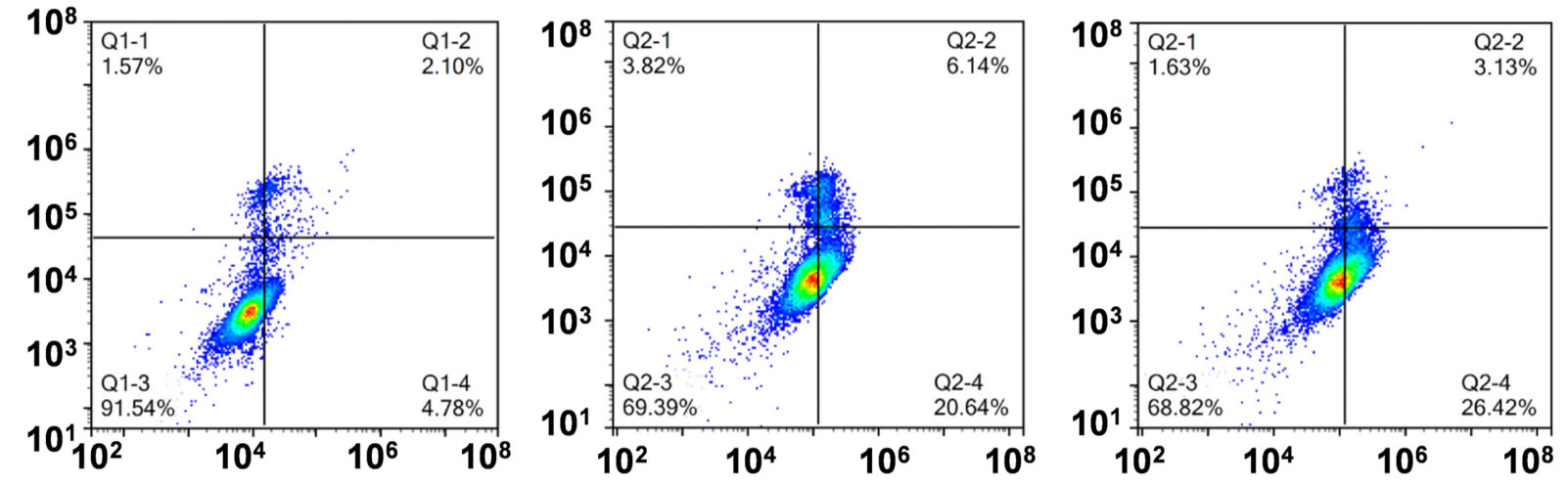

\section{Control}

\section{PI}

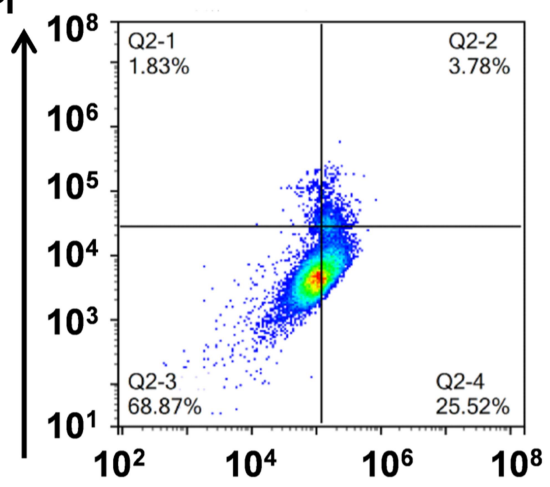

$0.5 \mathrm{~h}$

$1 \mathrm{~h}$

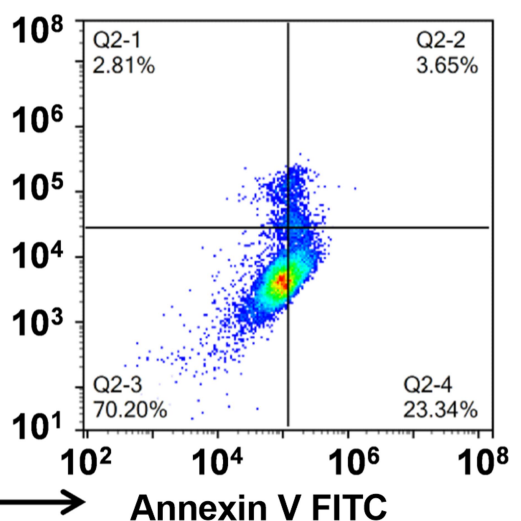

$2 \mathrm{~h}$

$4 \mathrm{~h}$

B

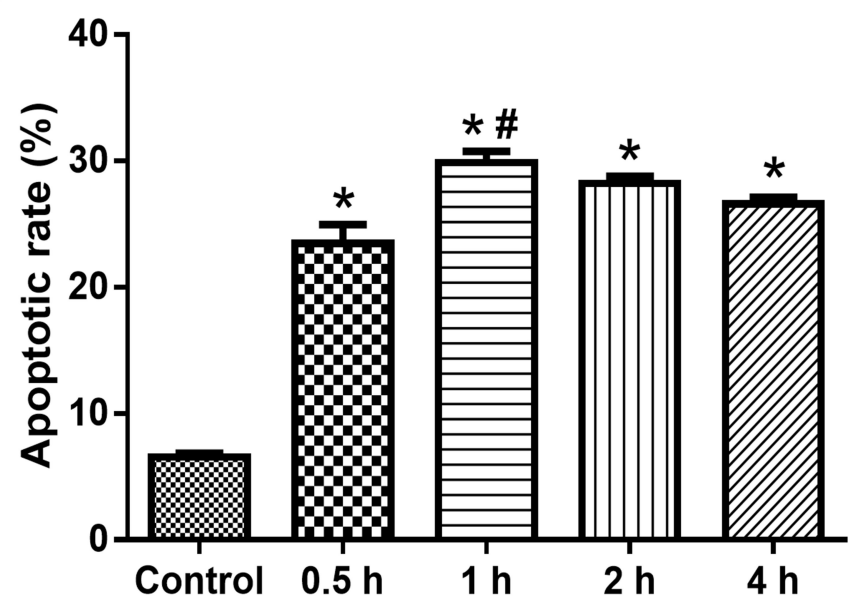

Figure I Determining the effect of PLA2 treatment by flow cytometry. (A) Representative images of flow cytometry; (B) Quantitative apoptosis data. Data were expressed as mean and standard deviation. $\mathrm{N}=6$ in each group (Bonferroni test). ${ }^{*} \mathrm{P}<0.05$ : compared with the control group; ${ }^{\#} \mathrm{P}<0.05$ : compared with $0.5 \mathrm{~h}$.

Abbreviations: PLA2, phospholipase A2; S, Sinonatrix peptide; B, Bungarus peptide.

group $(\mathrm{P}<0.05)$ (Figure 5A-C, Supplementary Figure S1). Compared with the model group, the groups treated with Sinonatrix and Bungarus peptides showed significantly decreased expression of p62, ATG5, and LC3-II/I $(\mathrm{P}<0.05)$.
Compared with the control group, the model group showed significantly increased expression of p62, ATG5, and LC3-II /I $(\mathrm{P}<0.05)$ (Figure 5D-F, Supplementary Figure S1). Compared with the model group, the expressions of $\mathrm{p} 62$, 

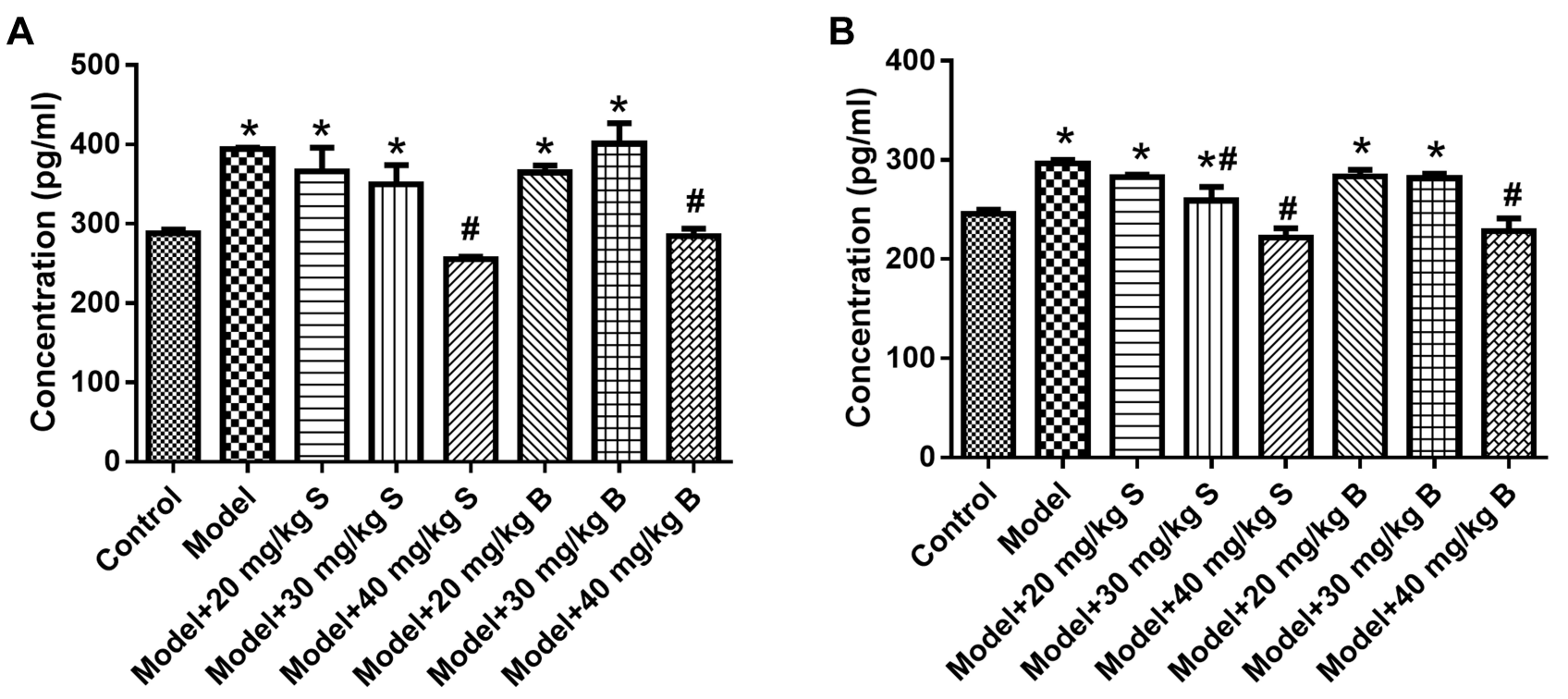

Figure 2 Effects of snake-derived PLIs on PAF and TNF- $\alpha$ levels in pancreatic tissue. (A) PAF level; (B) TNF- $\alpha$ level. Data were expressed as mean and standard deviation. $\mathrm{N}=6$ in each group (Bonferroni test). ${ }^{*} \mathrm{P}<0.05$ : compared with the control group; ${ }^{*} \mathrm{P}<0.05$ : compared with the model group.

Abbreviations: PAF, platelet-activating factor; PLIs, phospholipase A2 inhibitors; TNF, tumor necrosis factor; S, Sinonatrix peptide; B, Bungarus peptide.

ATG5, and LC3-II/I in the $40 \mathrm{mg} / \mathrm{kg}$ Sinonatrix peptide or $40 \mathrm{mg} / \mathrm{kg}$ Bungarus peptide groups decreased significantly $(\mathrm{P}<0.05)$.

\section{Discussion}

In this study, we verified that snake-derived PLI from common snake species in Jiangxi Province protected against classical features of AP. Moreover, Sinonatrix peptide or Bungarus peptide could reduce autophagy in PLA2-treated cells and the mouse model of AP. This study indicates snake-derived PLI from Sinonatrix percarinata and Bungarus multicinctus as candidate agents for AP.

Apoptosis is widespread in pancreatic acinar cells and extrapancreatic organs during the development of AP and is closely related to the degree of organ damage. ${ }^{17-19}$ Valentin et $\mathrm{al}^{20}$ verified that PLA2 receptor in snake venom or mammalian animals had high affinity, which suggested that the structure of PLA2 in snake venom is similar to that in humans and other mammals, and that snake-derived PLI may inhibit PLA2 in humans. As described previously, PLA2 levels in LPC-treated pancreatic acinar cells was remarkably promoted. Moreover, silencing PLA2 could prevent acute experimental pancreatitis in rats. ${ }^{12}$ Therefore, this study directly applied PLA2 to treat pancreatic acinar cells. SPLA2 is closely related to the occurrence and development of SAP, of which SPLA2-IB (pancreatic-derived PLA2) is mainly secreted by pancreatic acinar cells. sPLA2-IIA, also known as inflammatory PLA2, is expressed in a variety of cells. ${ }^{21}$ sPLA2 acts on phospholipids of the cell membrane to produce LPC and arachidonic acid (AA). The AA metabolic pathway is a classic pathway of human inflammation. ${ }^{22}$ In our study, we screened the optimal treatment period of PLA2. Our data showed that treatment with PLA2 for $1 \mathrm{~h}$ had optimal efficiency to trigger apoptosis in pancreatic acinar cells. Therefore, this regime was selected in subsequent experiments. For the in vivo model, we selected cerulein plus LPS to produce AP features in rats. Although the drugs used to establish the in vitro and in vivo models were different, the selected in vitro and in vivo models were classical and widely utilized to investigate the pathogenesis of AP or search for treatment methods. ${ }^{12}$ The mechanisms involved have some things in common, especially the inflammatory reaction. ${ }^{12}$ As reported previously, repeated injections of cerulein alone or cerulein plus LPS resulted in local inflammatory responses in the pancreas and corresponding systemic inflammatory changes with pronounced severity in the cerulein plus LPS group. ${ }^{12}$ Therefore, we selected the cerulein plus LPS model in this study.

PAF is produced by acetylation of LPC. PAF can cause platelet and neutrophil aggregation, increase vasodilation, endothelial permeability, and TNF- $\alpha$ levels. ${ }^{23}$ It has been found that snakes have a strong protective action against snake venom because of the PLI found in snake serum. ${ }^{24,25}$ 
A

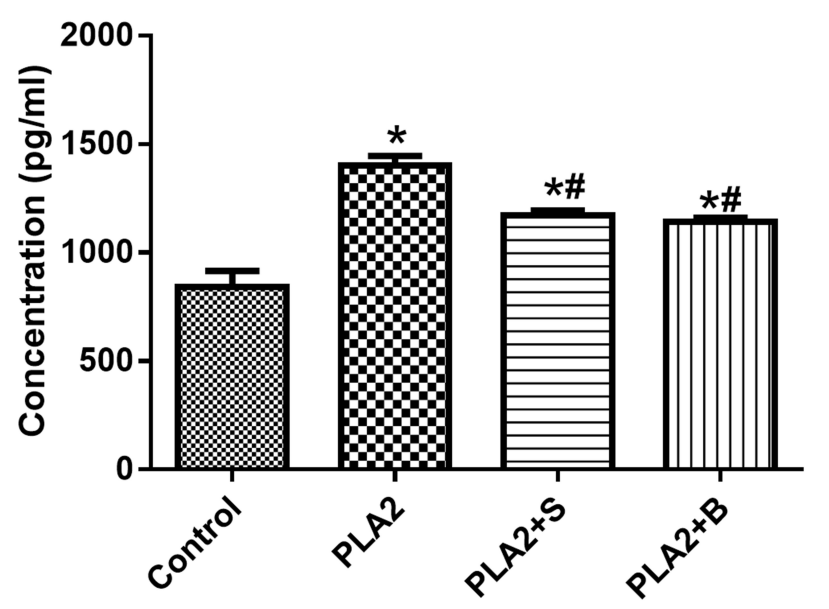

C

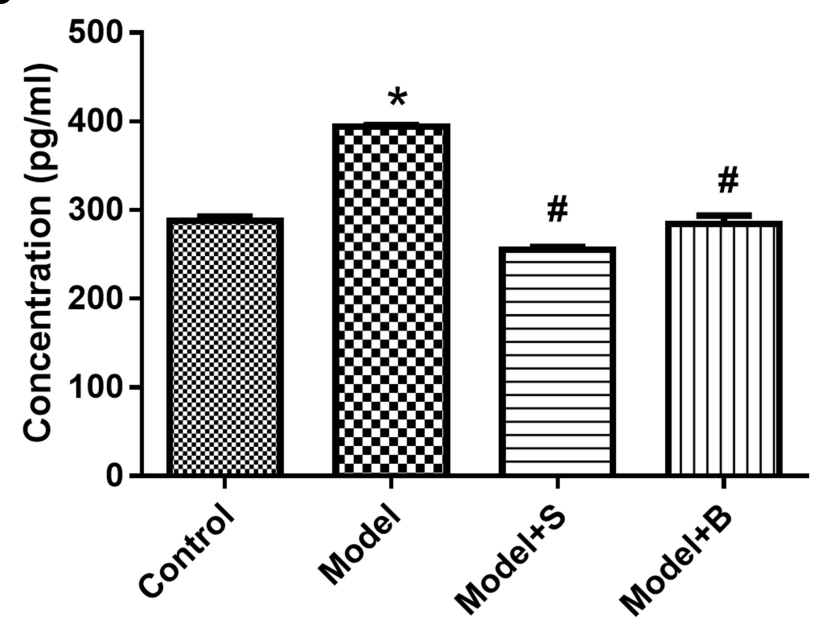

B

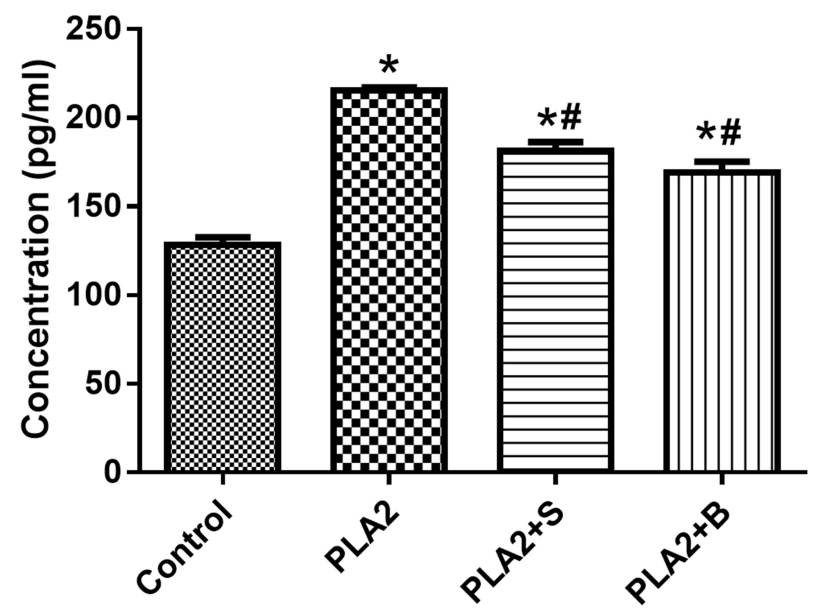

D

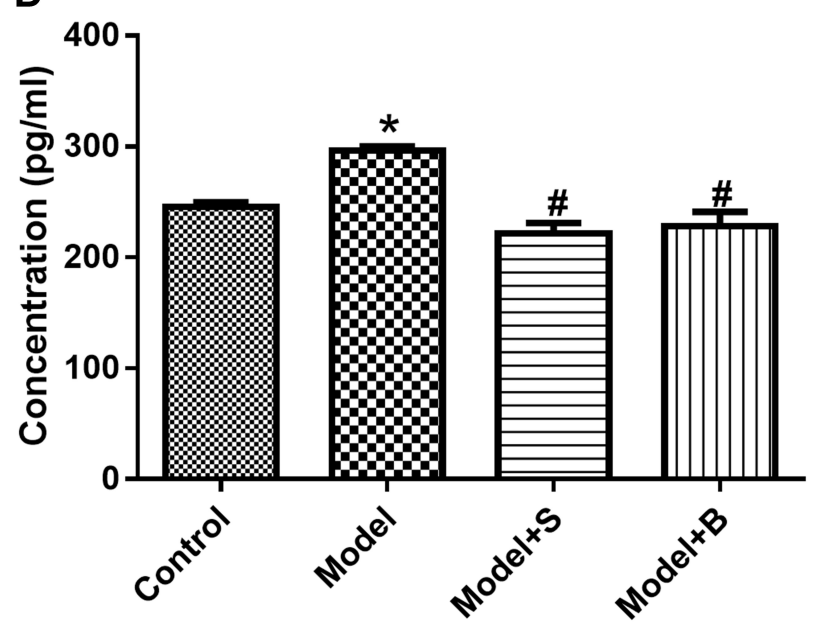

Figure 3 Snake-derived PLI reduced PAF and TNF- $\alpha$ levels in PLA 2-treated cells and AP mice model. (A, B) The level of PAF and TNF- $\alpha$ in the pancreatic acinar cells; (C, D) The level of PAF and TNF- $\alpha$ in vivo. Data were expressed as mean and standard deviation. $N=6$ in each group (Bonferroni test). $* P<0.05$ : compared with the control group; ${ }^{\#} \mathrm{P}<0.05$ : compared with the model group.

Abbreviations: PAF, platelet-activating factor; TNF, tumor necrosis factor; S, Sinonatrix peptide; B, Bungarus peptide.

In this study, Sinonatrix peptide and Bungarus peptide were prepared. Through the detection of PAF and TNF- $\alpha$ concentration, the appropriate dose of peptides for animal experiments was selected. In AP with brain injury, the permeability of the blood-brain barrier increases and toxic inflammatory factors including trypsin, elastase, phospholipase A2, vasokinin-releasing enzyme, cytokinin and pro-inflammatory cytokines (eg, TNF-a) infiltrate through cerebral veins, which can cause central vein thrombosis, neuronal swelling, metabolic disorders of central nervous system, brain hemorrhage, brain edema and softening, eventually leading to nervous system dysfunction. ${ }^{26}$ Farkas et al reported that the increase of serum TNF- $\alpha$ in pancreatitis model led to the increase of blood-brain barrier permeability and the occurrence of angiogenic brain edema. ${ }^{27}$ In this study, the concentration of PAF and TNF- $\alpha$ in pancreatic acinar cells treated with PLA2 increased, and the same results were obtained after the establishment of AP model in animals. Interestingly, the concentration of PAF and TNF- $\alpha$ was decreased with the appropriate use of Sinonatrix and Bungarus peptides. These results indicated that the concentration of PAF and TNF- $\alpha$ was increased when PLA2 was used to treat pancreatic acinar cells and the AP animal model, while the concentration of PAF and TNF- $\alpha$ was reduced by Sinonatrix and Bungarus peptides.

PLA2 is mainly responsible for intracellular phospholipid hydrolysis, which is related to intracellular inflammation and participates in the intracellular signaling 
A

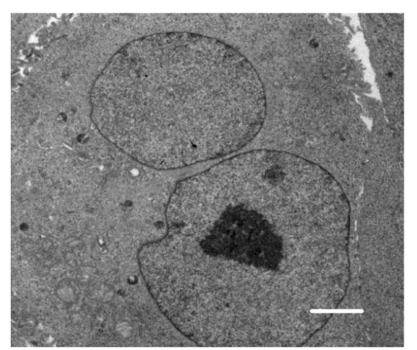

Control

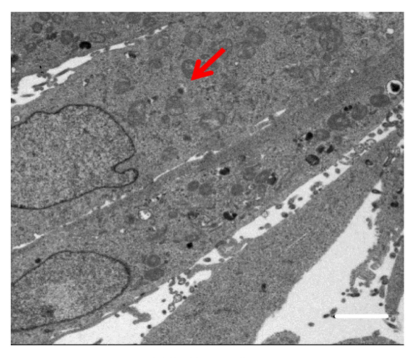

PLA2+S

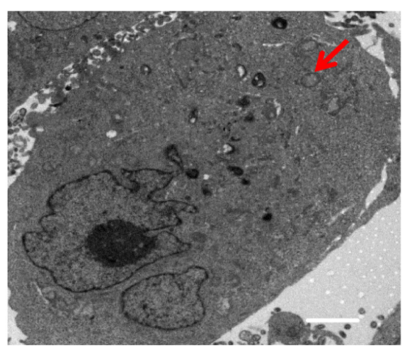

PLA2

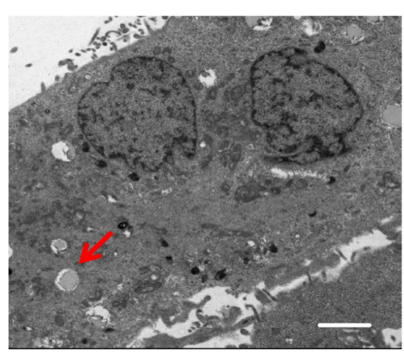

PLA2+B
B

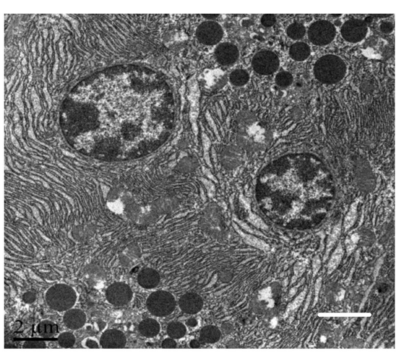

Control

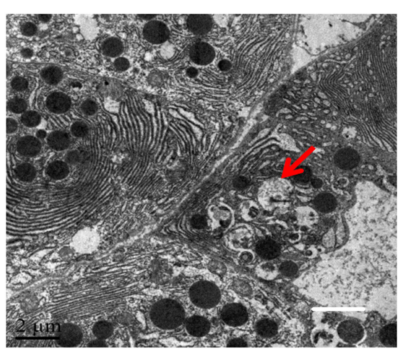

Model+S

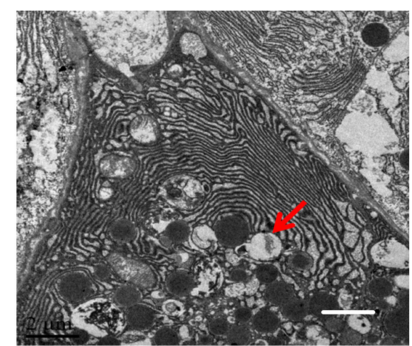

Model

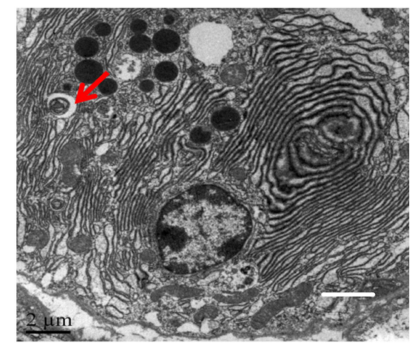

Model+B
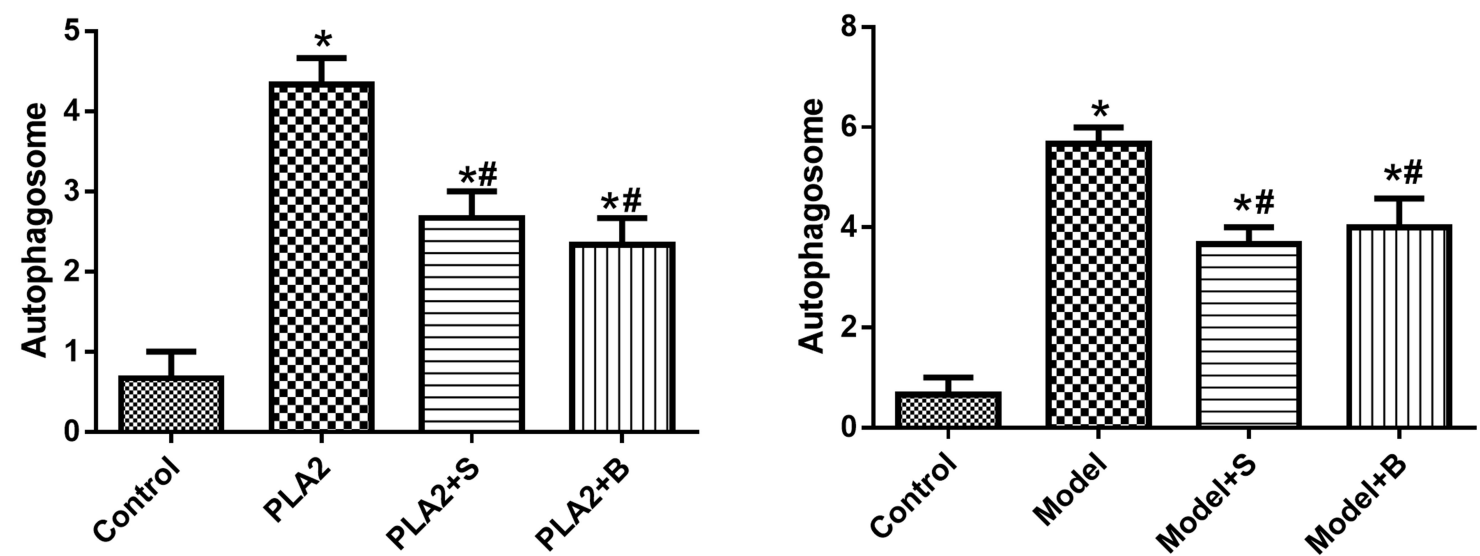

Figure 4 Snake-derived PLI reduced autophagic body formation in PLA 2-treated cells and AP mice model. (A) TEM results of cells; (B) TEM results of pancreatic tissue. Arrows indicate the autophagic bodies. ${ }^{*} \mathrm{P}<0.05$ : compared with the control group; ${ }^{\#} \mathrm{P}<0.05$ : compared with the model group.

Abbreviations: AP, acute pancreatitis; PLA2, phospholipase A2; TEM, transmission electron microscopy; S, Sinonatrix peptide; B, Bungarus peptide.

transduction, which is closely related to autophagy and necrosis. ${ }^{28}$ Compared with necrosis, autophagy has no cytoplasmic membrane destruction and is characterized by no tissue inflammatory response. ${ }^{29}$ Therefore, autophagic cell death is named as type II programmed death. During autophagy, organelles are degraded early, which is related to the hydrolysis of intracellular phospholipids by PLA2. It is also believed that PLA2 can damage cell organelles, especially mitochondria, and the accumulation of damaged mitochondria can promote cell death owing to reduced ATP and overproduction of ROS. However, normal autophagy can remove these damaged mitochondria, thus reducing the pathological response. ${ }^{30,31}$ In this study, remarkable autophagy occurred in pancreatic acinar cells treated with PLA2 and cells after the establishment of acute pancreatitis model, which resulted in the formation of autophagy; the number of autophagic bodies formed was significantly reduced after treatment with Sinonatrix peptide and Bungarus peptide, respectively. These results revealed that the autophagy of pancreatic acinar cells and AP animal models could be induced by PLA2. As evidenced, autophagy was abnormally promoted and autophagic cell death might be an important mechanism for the development of AP. ${ }^{32,33}$ Interestingly, snake-derived PLA2 inhibitors such as Sinonatrix peptide or Bungarus peptide could reduce autophagy of pancreatic acinar cells, which implied autophagy-inhibition as a potential protective mechanism. 


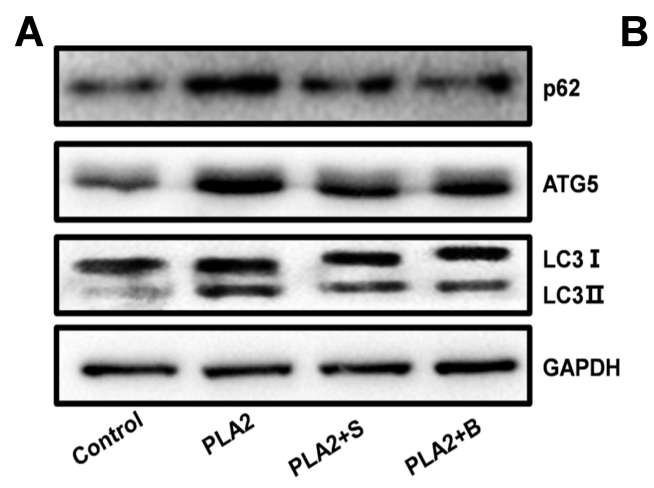

B
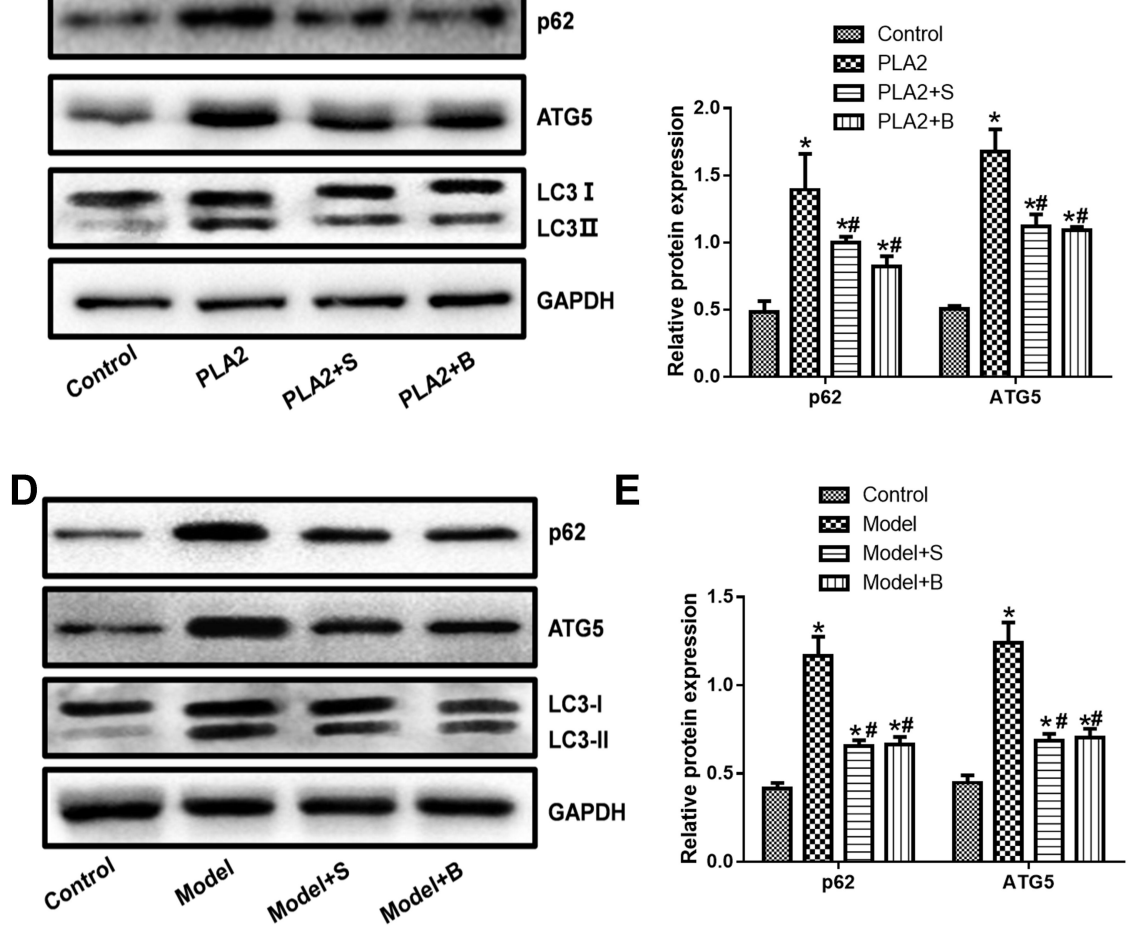

C

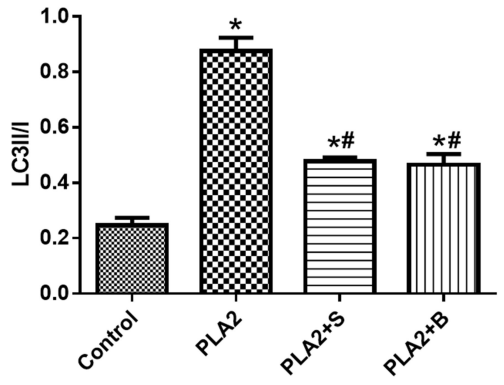

$\mathbf{F}$

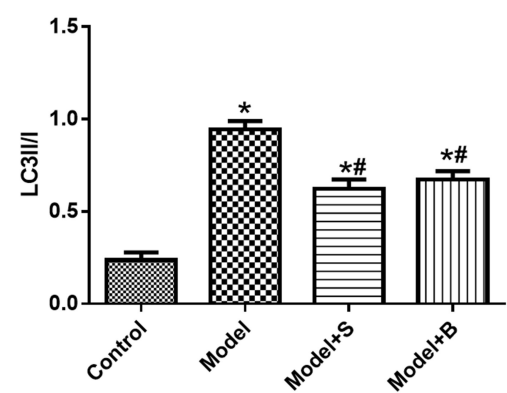

Figure 5 Snake-derived PLI reduced the expression of LC3, p62, and ATG5 in PLA 2-treated cells and AP mice model. (A-C) LC3, p62, and ATG5 in PLA 2-treated cells; (D-F) LC3, p62, and ATG5 in AP mice model. The original blots are shown in Supplementary Figure SI. Data were expressed as mean and standard deviation. N=6 in each group (Bonferroni test). ${ }^{*} \mathrm{P}<0.05$ : compared with the control group; ${ }^{\#} \mathrm{P}<0.05$ : compared with the model group.

Abbreviations: AP, acute pancreatitis; ATG5, autophagy-related 5; LC3, microtubule-associated protein IA/IB-light chain 3; S, Sinonatrix peptide; B, Bungarus peptide.

There were more autophagic vacuoles in the pancreatic acini in AP, and the degradation level of longevity protein and p62 was reduced. ${ }^{34}$ Beclin1 and LC3 in pancreatic tissue increased in rats with acute necrotizing pancreatitis, indicating that the activity of pancreatic autophagy increased in acute necrotizing pancreatitis, and its expression was related to the degree of inflammation. ${ }^{35}$ The increased autophagy may be a response to injury. It has also been suggested that the accumulation of autophagy vacuoles, reduction in the efficiency of autophagy degradation, and increase of LC-3II and p62 indicate that the function of autophagy is damaged. ${ }^{35,36} \mathrm{In}$ this study, the expression of Beclin1, LC3, and p62 increased after treatment of pancreatic acinar cells with PLA2 and in the AP animal model. The expression of Beclin1, LC3, and p62 decreased after treatment with Sinonatrix peptide and Bungarus peptide. These results indicated that the expression of Beclin 1, LC3, and p62 was increased when PLA2 was used to treat pancreatic acinar cells and AP in the mouse model, while the expression of Beclin 1, LC3 and p62 was inhibited by Sinonatrix peptide and Bungarus peptide.

There were some limitations in this study. First, although autophagy or autophagic cell death has been proposed as a pathogenesis of AP, the blockage of autophagy in physiological state could also contribute to the damage of pancreatic acinar cells. ${ }^{37}$ In future studies, the association of autophagy inhibition with treatment of Sinonatrix peptide and/or Bungarus peptide should be conducted to disclose the exact function of autophagy in the protection. Second, although AR42J cells were acknowledged cells with the characteristics of pancreatic acinar cells, ${ }^{12,13}$ it is more suitable to use the primary-cultured pancreatic acinar cells.

In conclusion, Sinonatrix peptide and Bungarus peptide could ameliorate the features of AP, likely through regulating autophagy. Our results suggest that snakederived PLI has the potential to treat AP.

\section{Data Sharing Statement}

The datasets used during the present study are available from the corresponding author upon reasonable request.

\section{Funding}

National Natural Science Foundation of China (81560112). 


\section{Disclosure}

All authors declare no personal, financial or non-financial conflicts of interest for this work.

\section{References}

1. Sun H, Zuo HD, Lin Q, et al. MR imaging for acute pancreatitis: the current status of clinical applications. Ann Transl Med. 2019;7 (12):269. doi:10.21037/atm.2019.05.37

2. Singh VK, Yadav D, Garg PK. Diagnosis and management of chronic pancreatitis: a review. JAMA. 2019;322(24):2422-2434. doi:10.1001/ jama.2019.19411

3. Gravante G, Garcea G, Ong SL, et al. Prediction of mortality in acute pancreatitis: a systematic review of the published evidence. Pancreatology. 2009;9(5):601-614. doi:10.1159/000212097

4. Hietaranta A, Kemppainen E, Puolakkainen P, et al. Extracellular phospholipases A2 in relation to systemic inflammatory response syndrome (SIRS) and systemic complications in severe acute pancreatitis. Pancreas. 1999;18(4):385-391. doi:10.1097/00006676199905000-00009

5. Xiao H, Pan H, Liao K, Yang M, Huang C. Snake venom PLA2, a promising target for broad-spectrum antivenom drug development Biomed Res Int. 2017;2017:6592820. doi:10.1155/2017/6592820

6. Koshy BS, Mahendra J. The association between periodontal status, serum lipid levels, lipoprotein associated phosholipase A2 (Lp-PLA2) in chronic periodontitis subjects and healthy controls. J Clin Diagn Res. 2017;11(9):ZC17-ZC21.

7. Zambelli VO, Picolo G, Fernandes CAH, Fontes MRM, Cury Y. Secreted phospholipases $\mathrm{A}(2)$ from animal venoms in pain and analgesia. Toxins. 2017;9(12):406. doi:10.3390/toxins9120406

8. Nolin JD, Lai Y, Ogden HL, et al. Secreted PLA2 group $\mathrm{X}$ orchestrates innate and adaptive immune responses to inhaled allergen. JCI Insight. 2017;2(21). doi:10.1172/jci.insight.94929.

9. Bastos VA, Gomes-Neto F, Perales J, Neves-Ferreira AG, Valente RH. Natural inhibitors of snake venom metalloendopeptidases: history and current challenges. Toxins. 2016;8(9):250. doi: $10.3390 /$ toxins 8090250

10. Giannotti KC, Leiguez E, Carvalho AEZ, et al. A snake venom group IIA PLA2 with immunomodulatory activity induces formation of lipid droplets containing 15-d-PGJ2 in macrophages. Sci Rep. 2017;7(1):4098. doi:10.1038/s41598-017-04498-8

11. Jackisch L, Kumsaiyai W, Moore JD, et al. Differential expression of Lp-PLA2 in obesity and type 2 diabetes and the influence of lipids. Diabetologia. 2018;61(5):1155-1166. doi:10.1007/s00125-018-45586

12. Zhang KJ, Zhang DL, Jiao XL, Dong C. Effect of phospholipase A2 silencing on acute experimental pancreatitis. Eur Rev Med Pharmacol Sci. 2013;17(24):3279-3284.

13. Masamune A, Sakai Y, Satoh A, Fujita M, Yoshida M, Shimosegawa T. Lysophosphatidylcholine induces apoptosis in AR42J cells. Pancreas. 2001;22(1):75-83. doi:10.1097/00006676200101000-00014

14. Hyun JJ, Lee HS. Experimental models of pancreatitis. Clin Endosc. 2014;47(3):212-216. doi:10.5946/ce.2014.47.3.212

15. Yang SJ, Song ZJ, Wang XC, Zhang ZR, Wu SB, Zhu GQ. Curculigoside facilitates fear extinction and prevents depression-like behaviors in a mouse learned helplessness model through increasing hippocampal BDNF. Acta Pharmacol Sin. 2019;40(10):1269-1278. doi:10.1038/s41401-019-0238-4

16. Song Z, Shen F, Zhang Z, Wu S, Zhu G. Calpain inhibition ameliorates depression-like behaviors by reducing inflammation and promoting synaptic protein expression in the hippocampus. Neuropharmacology. 2020;174:108175. doi:10.1016/j. neuropharm.2020.108175
17. Zhang H, Li Y, Li L, et al. Propylene glycol alginate sodium sulfate alleviates cerulein-induced acute pancreatitis by modulating the MEK/ERK pathway in mice. Mar Drugs. 2017;15(2):45. doi: $10.3390 / \mathrm{md} 15020045$

18. Li J, Yang S, Zhu G. Postnatal calpain inhibition elicits cerebellar cell death and motor dysfunction. Oncotarget. 2017;8(50):87997-88007. doi:10.18632/oncotarget.21324

19. Cui L, Liu R, Li C, et al. Angiotensin(17) attenuates caerulein induced pancreatic acinar cell apoptosis. Mol Med Rep. 2017;16 (3):3455-3460. doi:10.3892/mmr.2017.6982

20. Valentin E, Koduri RS, Scimeca JC, et al. Cloning and recombinant expression of a novel mouse-secreted phospholipase A2. $J$ Biol Chem. 1999;274(27):19152-19160. doi:10.1074/ jbc.274.27.19152

21. Liu CW, Sung HC, Lin SR, et al. Resveratrol attenuates ICAM-1 expression and monocyte adhesiveness to TNF-alpha-treated endothelial cells: evidence for an anti-inflammatory cascade mediated by the miR-221/222/AMPK/p38/NF-kappaB pathway. Sci Rep. 2017;7(1):44689. doi:10.1038/srep44689

22. Giri S, Khan M, Rattan R, Singh I, Singh AK. Krabbe disease: psychosine-mediated activation of phospholipase A2 in oligodendrocyte cell death. J Lipid Res. 2006;47(7):1478-1492. doi:10.1194/jlr. M600084-JLR200

23. Stokes KY, Granger DN. Platelets: a critical link between inflammation and microvascular dysfunction. $J$ Physiol. 2012;590 (5):1023-1034.

24. Shimada A, Ohkura N, Hayashi K, et al. Subunit structure and inhibition specificity of alpha-type phospholipase A2 inhibitor from protobothrops flavoviridis. Toxicon. 2008;51(5):787-796. doi:10.1016/j.toxicon.2007.12.014

25. So S, Chijiwa T, Ikeda N, et al. Identification of the B subtype of gamma-phospholipase A2 inhibitor from protobothrops flavoviridis serum and molecular evolution of snake serum phospholipase A2 inhibitors. J Mol Evol. 2008;66(3):298-307. doi:10.1007/s00239-0089089-1

26. Ha XQ, Song YJ, Zhao HB, et al. Endothelial progenitor cells in peripheral blood may serve as a biological marker to predict severe acute pancreatitis. World J Gastroenterol. 2017;23(14):2592-2600. doi:10.3748/wjg.v23.i14.2592

27. Farkas G, Marton J, Nagy Z, et al. Experimental acute pancreatitis results in increased blood-brain barrier permeability in the rat: a potential role for tumor necrosis factor and interleukin 6 . Neurosci Lett. 1998;242(3):147-150.

28. Qasem H, Al-Ayadhi L, Al Dera H, El-Ansary A. Increase of cytosolic phospholipase A2 as hydrolytic enzyme of phospholipids and autism cognitive, social and sensory dysfunction severity. Lipids Health Dis. 2017;16(1):117. doi:10.1186/ s12944-016-0391-4

29. Lu K, Wang H, Ge X, et al. Hyperbaric oxygen protects against cerebral damage in permanent middle cerebral artery occlusion rats and inhibits autophagy activity. Neurocrit Care. 2019;30(1):98-105. doi:10.1007/s12028-018-0577-x

30. Rukoyatkina N, Mindukshev I, Walter U, Gambaryan S. Dual role of the $\mathrm{p} 38 \mathrm{MAPK} / \mathrm{cPLA} 2$ pathway in the regulation of platelet apoptosis induced by ABT-737 and strong platelet agonists. Cell Death Dis. 2013;4(11):e931. doi:10.1038/cddis.2013.459

31. Green DR, Galluzzi L, Kroemer G. Mitochondria and the autophagy-inflammation-cell death axis in organismal aging. Science. 2011;333(6046):1109-1112. doi:10.1126/science.1201940

32. Fan HN, Chen W, Fan LN, Wu JT, Zhu JS, Zhang J. Macrophagesderived p38alpha promotes the experimental severe acute pancreatitis by regulating inflammation and autophagy. Int Immunopharmacol. 2019;77:105940. doi:10.1016/j.intimp.2019.105940

33. Shen S, Li B, Dai J, et al. BRD4 inhibition protects against acute pancreatitis through restoring impaired autophagic flux. Front Pharmacol. 2020;11:618. doi:10.3389/fphar.2020.00618 
34. Mareninova OA, Hermann K, French SW, et al. Impaired autophagic flux mediates acinar cell vacuole formation and trypsinogen activation in rodent models of acute pancreatitis. J Clin Invest. 2009;119 (11):3340-3355.

35. Gukovskaya AS, Gukovsky I, Algul H, Habtezion A. Autophagy, inflammation, and immune dysfunction in the pathogenesis of pancreatitis. Gastroenterology. 2017;153(5):1212-1226.
36. Gukovsky I, Pandol SJ, Mareninova OA, Shalbueva N, Jia W, Gukovskaya AS. Impaired autophagy and organellar dysfunction in pancreatitis. J Gastroenterol Hepatol. 2012;27(Suppl 2):27-32. doi:10.1111/j.1440-1746.2011.07004.x

37. Mareninova OA, Jia W, Gretler SR, et al. Transgenic expression of GFP-LC3 perturbs autophagy in exocrine pancreas and acute pancreatitis responses in mice. Autophagy. 2020;1-14.

\section{Publish your work in this journal}

Drug Design, Development and Therapy is an international, peerreviewed open-access journal that spans the spectrum of drug design and development through to clinical applications. Clinical outcomes, patient safety, and programs for the development and effective, safe, and sustained use of medicines are a feature of the journal, which has also been accepted for indexing on PubMed Central. The manuscrip management system is completely online and includes a very quick and fair peer-review system, which is all easy to use. Visit http://www. dovepress.com/testimonials.php to read real quotes from published authors. 